\title{
Correction to: A Lagrangian analysis of the gravity-inertial oil spreading on the calm sea using the reflective oil-water interface treatment
}

\author{
Carlos Alberto Dutra Fraga Filho ${ }^{1}$ \\ Published online: 3 June 2021 \\ (C) Springer-Verlag GmbH Germany, part of Springer Nature 2021
}

Correction to: Environmental Science and Pollution Research (2021) 28:17170-17180 https://doi.org/10.1007/s11356-020-11508-2

Unfortunately, in the original paper, on page 17178, was printed "( $0.82 \mathrm{~s}$, predicted by Eq. (Undefined control sequence IvarDelta11))" and should be "(0.82 s, predicted by Eq. (13))".

On page 17180, in the reference Fraga Filho CAD (2017a), "Hannoner" should be "Hannover".

Publisher's note Springer Nature remains neutral with regard to jurisdictional claims in published maps and institutional affiliations.

The online version of the original article can be found at https://oi.org/ $10.1007 / \mathrm{s} 11356-020-11508-2$

Carlos Alberto Dutra Fraga Filho cadff1@gmail.com

1 Federal Institute of Education, Science and Technology of Espírito Santo (IFES) - Mechanical Coordination, Alameda Francisco Vieira Simões, 720, Aeroporto, Guarapari, ES 29216-795, Brazil 